\title{
UDP-Glycosyltransferase 3A Metabolism of Polycyclic Aromatic Hydrocarbons: Potential Importance in Aerodigestive Tract Tissues ${ }^{\sqrt{\text { [ }}}$
}

\author{
(D)Ana G. Vergara, (D)Christy J.W. Watson, (D)Gang Chen, and (DPhilip Lazarus \\ Department of Pharmaceutical Sciences, College of Pharmacy and Pharmaceutical Sciences, Washington State University, \\ Spokane, Washington
}

Received September 5, 2019; accepted November 27, 2019

\section{ABSTRACT}

Polycyclic aromatic hydrocarbons (PAHs) are potent carcinogens and are a primary risk factor for the development of lung and other aerodigestive tract cancers in smokers. The detoxification of PAHs by glucuronidation is well-characterized for the UDPglycosyltransferase (UGT) 1A, 2A, and 2B subfamilies; however, the role of the UGT3A subfamily in PAH metabolism remains poorly understood. UGT3A enzymes are functionally distinct from other UGT subfamilies (which use UDP-glucuronic acid as a cosubstrate) due to their utilization of alternative cosubstrates (UDP-Nacetylglucosamine for UGT3A1, and UDP-glucose and UDP-xylose for UGT3A2). The goal of the present study was to characterize UGT3A glycosylation activity against PAHs and examine their expression in human aerodigestive tract tissues. In vitro metabolism assays using UGT3A2-overexpressing cell microsomes indicated that UGT3A2 exhibits glycosylation activity against all of the simple and complex PAHs tested. The $V_{\max } / K_{m}$ ratios for UGT3A2 activity with UDP-xylose versus UDP-glucose as the cosubstrate ranged from 0.65 to 4.4 for all PAHs tested, demonstrating that PAH glycosylation may be occurring at rates up to 4.4-fold higher with UDP-xylose than with UDP-glucose. Limited glycosylation activity was observed against PAHs with UGT3A1-overexpressing cell microsomes. While UGT3A2 exhibited low levels of hepatic expression, it was shown by western blot analysis to be widely expressed in aerodigestive tract tissues. Conversely, UGT3A1 exhibited the highest expression in liver with lower expression in aerodigestive tract tissues. These data suggest that UGT3A2 plays an important role in the detoxification of PAHs in aerodigestive tract tissues, and that there may be cosubstrate-dependent differences in the detoxification of PAHs by UGT3A2.

\section{SIGNIFICANCE STATEMENT}

UGT3A2 is highly active against PAHs with either UDP-glucose or UDP-xylose as a cosubstrate. UGT3A1 exhibited low levels of activity against PAHs. UGT3A1 is highly expressed in liver while UGT3A2 is well expressed in extrahepatic tissues. UGT3A2 may be an important detoxifier of PAHs in humans.

\section{Introduction}

Tobacco smoke contains over 4800 compounds with at least 69 identifiable carcinogens (Hoffmann et al., 2001). One of the most potent and abundant groups of tobacco carcinogens are the polycyclic aromatic hydrocarbons (PAHs), which are classified as group 1, 2A, or $2 \mathrm{~B}$ carcinogens by the International Agency for Research on Cancer (Hecht,

This work was supported by the National Institutes of Health National Institutes of Environmental Health Sciences [Grants R01-ES025460 and R01-ES02546002S1]; the Health Sciences and Services Authority of Spokane, WA [Grant WSU002292]; and the synthesis of UDP-xylose by CarboSource Services, supported in part by the National Science Foundation Research Coordination Networks [Grant 0090281].

Part of this work was presented as follows: Vergara AG, Watson CJW, and Lazarus $P$ (2017) Characterization of UDP-glycosyltransferase 3A (UGT3A) variants in tobacco carcinogen metabolism. FASEB J. 31 (1 Suppl):821.2; and Vergara AG, Watson CJW, Chen G, and Lazarus P (2019) Glycosylation of polycyclic aromatic hydrocarbons by UDP-glycosyltransferase 3A2 (UGT3A2) and aerodigestive tract tissues. FASEB J. 33 (1 Suppl):673.9.

https://doi.org/10.1124/dmd.119.089284.

S This article has supplemental material available at dmd.aspetjournals.org.
1999). In addition to being present in tobacco smoke, PAHs are produced by incomplete combustion of organic compounds including wood, coal, oil, and gasoline, and many food sources, and humans are exposed to PAHs on a regular basis through air, water, soil, and food sources by ingestion, inhalation, and dermal contact (Mumtaz et al., 1996). The amount of carcinogenic PAHs found in the smoke of a single nonfiltered cigarette varies from 80 to $160 \mu \mathrm{g} /$ cigarette, with one of the highest concentrations observed for benzo(a)pyrene (BaP): 20-40 ng/ cigarette (Hoffmann et al., 2001). While other PAHs, including dibenzo $(a, l)$ pyrene (DB $a l \mathrm{P})$ and 5-methylchrysene (5-MeC), are stronger lung tumorigens than $\mathrm{B} a \mathrm{P}$ in rodent models, they are far less abundant in tobacco smoke (1.7-3.2 ng/cigarette for DBalP and $0.6 \mathrm{ng} /$ cigarette for 5-MeC) (Sellakumar and Shubik, 1974; Nesnow et al., 1995; Prahalad et al., 1997; Hecht, 1999; Hoffmann et al., 2001). Nonsmokers can receive up to $70 \%$ of their PAH exposure through their diet, with high levels found in meat products $(13-26 \mu \mathrm{g} / \mathrm{kg})$, seafood (8.0-71 $\mu \mathrm{g} / \mathrm{kg})$, cereals (15-44 $\mu \mathrm{g} / \mathrm{kg})$, and oils/fats $(24 \mu \mathrm{g} / \mathrm{kg})($ Choi et al., 2010). Smokers are exposed to higher levels of PAHs than nonsmokers, with urinary PAH metabolites 1.5- to 6.9-fold higher compared with nonsmokers (Suwan-ampai et al., 2009).

ABBREVIATIONS: BaP, benzo(a)pyrene; BaP-7,8-diol, trans-7,8-dihydroxy-7,8-dihydro- benzo(a)pyrene; BaP-9,10-diol, benzo(a)pyrene-trans9,10-dihydrodiol; DBa/P, dibenzo(a,/)pyrene; DBalP-11,12-diol, trans-11,12-dihydroxy-11,12-dihydrodibenzo(a,/)pyrene; HEK293, human embryonic kidney 293; 5-MeC, 5-methylchrysene; 5-MeC-1,2-diol, 1,2-dihydro-1,2-dihydroxy-5-methylchrysene; 1-OH-pyrene, 1-hydroxypyrene; PAH, polycyclic aromatic hydrocarbon; PCR, polymerase chain reaction; TBS, Tris-buffered saline; UDP-Glc, UDP-glucose; UDP-GlcNAc, UDP$\mathrm{N}$-acetylglucosamine; UDP-GlcUA, UDP-glucuronic acid; UDP-Xyl, UDP-xylose; UGT, UDP-glycosyltransferase. 
The major carcinogen activation pathway for PAHs is via the cytochrome P450 (CYP) class of enzymes, with biotransformation of $\mathrm{B} a \mathrm{P}$ by several CYP enzymes, including $1 \mathrm{~A} 1$ and $1 \mathrm{~B} 1$, to form hydroxylated or epoxide forms (Shimada et al., 1996; Kim et al., 1998). B $a$ P epoxides are hydrolyzed by microsomal epoxide hydrolase to form $\mathrm{B} a \mathrm{P}$-diols, which can undergo further metabolism by CYP1A1, $1 \mathrm{~B} 1$, and $3 \mathrm{~A} 4$ to $\mathrm{B} a \mathrm{P}$-diol-epoxides, many of which are capable of forming PAH-DNA adducts (Thakker et al., 1977; Levin et al., 1980; Trushin et al., 2012). The carcinogenicity of PAHs is dependent on the number of benzenoid rings, their ring structure (fjord vs. bay regions), and having metabolites that can form DNA adducts (Moorthy et al., 2015; Gao et al., 2018). DBalP is the most carcinogenic PAH because it has a fjord region that is nonplanar, reactive, and binds preferentially to adenine nucleotides (Ewa and Danuta, 2017). In contrast, 5-MeC and $\mathrm{B} a \mathrm{P}$ have a bay region that is planar, less reactive, and binds to guanine nucleotides; 5-MeC is more carcinogenic than $\mathrm{B} a \mathrm{P}$ because it has a methylated bay region and an additional bay region (Palackal et al., 2002; Ewa and Danuta, 2017).

A major mode of detoxification of PAHs is by the phase II family of UDP-glycosyltransferases (UGTs). While extensive studies have examined the UGT1A, 2A, and 2B enzyme subfamilies for activity against PAHs (Jin et al., 1993; Fang et al., 2002; Uchaipichat et al., 2004; Finel et al., 2005; Luukkanen et al., 2005; Dellinger et al., 2006; Itäaho et al., 2010; Bushey et al.,2011, 2013; Olson et al., 2011), few studies have examined the activity of UGT3A enzymes against these carcinogenic compounds. Unlike other UGT enzymes which use UDP-glucuronic acid (UDP-GlcUA) as a cosubstrate, the UGT3A enzymes are unique from other UGTs in that they use alternative sugars as cosubstrates, with UGT3A1 using UDP- $N$-acetylglucosamine (UDP-GlcNAc) and UGT3A2 using UDP-glucose (UDP-Glc) or UDP-xylose (UDP-Xyl) (Mackenzie et al., 2008, MacKenzie et al., 2011). While UGT3A1 was shown to be expressed in liver and kidney and to a lesser extent in testes, colon, and duodenum, UGT3A2 was found to be primarily an extrahepatic enzyme (Mackenzie et al., 2008, MacKenzie et al., 2011).

In a screening of their activity against a variety of substrates, UGT3A1 and $3 \mathrm{~A} 2$ both exhibited glycosylic activity against the simple PAHs 1naphthol and 1-hydroxypyrene (1-OH-pyrene) (Mackenzie et al., 2008, MacKenzie et al., 2011; Meech and Mackenzie, 2010; Meech et al., 2012). The goals of the present study were to better characterize UGT3A activity against more complex PAHs and to examine their expression in human aerodigestive tract tissues, which are target sites of $\mathrm{PAH}$ carcinogenicity.

\section{Materials and Methods}

Chemicals and Reagents. The RNeasy Mini Kit was purchased from Qiagen (Valencia, CA). SuperScript II reverse transcriptase, Platinum Taq DNA polymerase, the pcDNA3.1/V5-His TOPO TA Expression Kit, One Shot TOP10 competent Escherichia coli, Lipofectamine 2000, the PureLink Genomic DNA Mini Kit, Invitrolon Polyvinylidene diflouride/Filter Paper Sandwich, and the Novex ECL Chemiluminescent Substrate Reagent Kit were obtained from Invitrogen (Carlsbad, CA). Oligonucleotides for polymerase chain reaction (PCR) were purchased from Integrated DNA Technologies (Coralville, IA). The GeneJet Gel Extraction and DNA Cleanup Micro Kit, GeneJet Plasmid Mini and Midi Kit, Pierce BCA Protein Assay Kit, and Gelcode Blue Stain Reagent were purchased from Thermo Scientific (Waltham, MA). Dulbecco's modified Eagle's medium, Dulbecco's PBS, and geneticin were purchased from Gibco (Grand Island, NY). Premium grade FBS was purchased from Seradigm (Radnor, PA) and ChromatoPur bovine albumin was purchased from MB Biomedicals (Santa Ana, CA).

The UGT3A2 antibody was purchased from Santa Cruz Biotechnology (Dallas, TX), while donkey anti-goat IgG horseradish peroxidase conjugate, anti- $\beta$-actin, rabbit anti-mouse $\operatorname{IgG}$ horseradish peroxidase conjugate, and goat anti-rabbit horseradish peroxidase conjugate were purchased from Thermo Fisher
Scientific (Rockford, IL). UDP-Glc and anti-UGT3A1 antibody were purchased from Abcam (Cambridge, MA). UDP-Xyl was purchased from Carbosource Services (Athens, GA). 1-OH-pyrene, 1-naphthol, alamethicin, ampicillin, UDPGlcNAc, and $\beta$ - $N$-acetylglucosaminidase were purchased from Sigma-Aldrich (St. Louis, MO). $\beta$-Glucosidase and exo-1,4- $\beta$-D-xylosidase were purchased from Megazyme (Bray, Ireland). 1-OH-B $a$ P, 7-OH-B $a \mathrm{P}, 8-\mathrm{OH}-\mathrm{B} a \mathrm{P}, 9-\mathrm{OH}-\mathrm{B} a \mathrm{P}$, $\mathrm{B}(a) \mathrm{P}-$ trans-9,10-dihydrodiol (BaP-9,10-diol), trans-11,12-dihydroxy-11,12dihydrodibenzo( $a, l$ )pyrene (DBalP-11,12-diol), and 1,2-dihydro-1,2-dihydroxy5-methylchrysene (5-MeC-1,2-diol) were purchased from MRI Global (Kansas City, MO). 3-OH-B $a \mathrm{P}$ and trans-7,8-dihydroxy-7,8-dihydro-B $(a) \mathrm{P}(\mathrm{B} a \mathrm{P}-7,8-$ diol) were purchased from Toronto Research Chemicals (North York, ON, Canada). High-performance liquid chromatography grade ammonium acetate and Optima acetonitrile were purchased from Fisher Scientific (Pittsburgh, PA).

Tissues. Normal human tissue specimens were obtained from the Banner Sun Health Research Institute (Sun City, AZ), the Cooperative Human Tissue Network Eastern Division (Philadelphia, PA), or the H. Lee Moffitt Cancer Center (Tampa, FL), and were isolated postsurgery or postmortem within 3 hours and frozen at $-80^{\circ} \mathrm{C}$. Mixed tissues selected for this study were primarily from the respiratory tract [lung $(n=5)$, trachea $(n=4)$, tongue $(n=3)$, floor of mouth $(n=2)$, tonsil $(n=5)$, larynx $(n=4)$, and esophagus $(n=5)]$, digestive tract [jejunum $(n=5)$, colon $(n=5)$, and liver $(n=5)$ ], and breast $(n=5)$. The demographic information for these human tissues is described in Supplemental Table 1. Of the tissue samples where demographic information was obtained, $51 \%$ were female, with $80 \%$ from Whites and $20 \%$ from Blacks.

Normal human kidney total RNA was purchased from Stratagene (La Jolla, CA); total RNA was extracted using standard protocols from normal human liver tissue obtained from the Penn State University College of Medicine Tissue Bank. All protocols involving the analysis of tissue specimens from these tissue banks were approved by the institutional review board at Washington State University in accordance with assurances filed with and approved by the U.S. Department of Health and Human Services.

Generation of UGT3A-Overexpressing Cell Lines. A stable human embryonic kidney 293 (HEK293) cell line overexpressing UGT3A1 was generated using standard protocols. Normal human liver total RNA $(2 \mu \mathrm{g})$ was extracted using an RNeasy Mini Kit from normal human liver tissue, which was used as a template in a reverse transcription reaction containing SuperScript II reverse transcriptase (200 U). cDNA corresponding to $200 \mathrm{ng}$ total liver RNA was used with 2.5 U of Platinum Taq DNA polymerase for the PCR amplification of UGT3A1. The primers used to amplify UGT3A1 from liver cDNA were $5^{\prime}$-TGC TTCTGTGGAAGTGAGCATGGT-3' (sense) and 5'-AGCCTCATGTCTTCT TCACCTTC-3' (antisense), corresponding to nucleotides -19 to +5 and +1576 to +1554 , respectively, relative to the UGT3A1 translation start site. PCR was performed with an initial denaturation temperature of $94^{\circ} \mathrm{C}$ for 2 minutes, 40 cycles of $94^{\circ} \mathrm{C}$ for 30 seconds, $57^{\circ} \mathrm{C}$ for 40 seconds, and $72^{\circ} \mathrm{C}$ for 1 minute and 45 seconds, followed by a final cycle of 10 minutes at $72^{\circ} \mathrm{C}$. The UGT3A1 sequence was verified by Sanger sequencing (Genewiz, South Plainfield, NJ) and compared with that described for UGT3A1 in GenBank (NM_152404.3). The sequencing results revealed that the UGT3A1 insert contained a synonymous C1320T nucleotide change, which maintained the alanine at amino acid residue 430. The UGT3A1 insert was cloned into a pcDNA3.1/V5-His-TOPO vector using standard protocols. After transformation using One Shot TOP10 competent E. coli, transformants were grown on plates containing LB agar and ampicillin $(100 \mu \mathrm{g} / \mathrm{ml})$ and confirmed by Sanger sequencing. Lipofectamine 2000 was used to transfect $8 \mu \mathrm{g}$ of pcDNA3.1/V5-His-TOPO/UGT3A1 plasmid into HEK293 cells purchased from American Type Culture Collection (Manassas, VA). The HEK293 cell line was authenticated by American Type Culture Collection using short-tandem repeat polymorphisms analysis in December 2017. Stable cell lines were grown in Dulbecco's modified Eagle's medium supplemented with $10 \%$ FBS and $700 \mu \mathrm{g} / \mathrm{ml}$ of geneticin. Genomic DNA was extracted from the stable cell line using the PureLink Genomic DNA Mini Kit and Sanger sequencing was used to confirm the presence and identity of the UGT3A1 cDNA sequence.

The UGT3A2 overexpressing HEK293 cell line was generated by reverse transcription PCR as described previously using normal human total kidney RNA $(2 \mu \mathrm{g})$ as the template for reverse transcription. The primers used to amplify UGT3A2 from kidney cDNA were 5'-GGCTTCCGTAGAAGTGAGCATG-3' (sense) and 5' -CCTGGCCTTATGTCTCCTTCACC-3' (antisense), corresponding to nucleotides -19 to +3 and +1579 to +1557 , respectively, relative to the 
UGT3A2 translation start site. PCR was performed with an initial denaturation temperature of $94^{\circ} \mathrm{C}$ for 2 minutes, 40 cycles of $94^{\circ} \mathrm{C}$ for 30 seconds, $57^{\circ} \mathrm{C}$ for 40 seconds, and $72^{\circ} \mathrm{C}$ for 2 minutes, followed by a final cycle of 10 minutes at $72^{\circ} \mathrm{C}$. The PCR product was excised and purified from an agarose gel using the GeneJet Gel Extraction Kit. The purified PCR product was verified by Sanger sequencing and was found to be identical to the reference UGT3A2 cDNA sequence (NM_174914.3). The verified UGT3A2 cDNA was cloned into the pcDNA3.1/ V5-His-TOPO vector and overexpressed in HEK293 cells as described previously for UGT3A1. The UGT3A2-overexpressing HEK293 cell line was verified by Sanger sequencing.

Analysis of UGT3A Protein Expression. For UGT-overexpressing cell lines, whole cell homogenates and S9 and microsomal fractions were prepared through differential centrifugation utilizing methods adapted from a previous study (Dellinger et al., 2007). Briefly, cell homogenates were prepared by resuspending pelleted cells in Tris-buffered saline [(TBS); $25 \mathrm{mM}$ Tris base, $138 \mathrm{mM} \mathrm{NaCl}$, and $2.7 \mathrm{mM} \mathrm{KCl}(\mathrm{pH} 7.4)$ ], followed by five rounds of freeze-thaw cycles prior to gentle homogenization. The $\mathrm{S} 9$ fraction was prepared by centrifuging the cell homogenate at $9000 \mathrm{~g}$ for 30 minutes at $4^{\circ} \mathrm{C}$. The $\mathrm{S} 9$ fraction was further processed by ultracentrifugation at $105,000 \mathrm{~g}$ for 1 hour at $4{ }^{\circ} \mathrm{C}$, and the microsomal pellet was resuspended in TBS. Total protein concentrations were determined using the Pierce BCA Protein Assay Kit.

Western blot analysis was performed using $20 \mu \mathrm{g}$ of total protein homogenate utilizing a $10 \%$ SDS-polyacrylamide gel, which was subsequently transferred to an Invitrolon Polyvinylidene difluoride membrane. For UGT3A1, membranes were blocked with a 5\% solution of milk in TBS containing $0.1 \%$ Tween 20 and probed with a rabbit monoclonal UGT3A1 antibody (1:1500 dilution), followed by a goat anti-rabbit secondary antibody (1:1000 dilution). For UGT3A2, the membrane was blocked with a $5 \%$ solution of ChromatoPur bovine albumin in TBS containing $0.1 \%$ Tween 20 and probed with goat polyclonal UGT3A2 antibody (1:1000 dilution), followed by a donkey anti-goat secondary antibody (1:2500 dilution). The $\beta$-actin antibody (1:5000 dilution) was used to verify equal loading using the rabbit anti-mouse secondary antibody (1:10,000 dilution) for both the UGT3A1 and UGT3A2 western blots. Immunocomplexes were visualized with the Novex ECL Chemiluminescent Kit following the manufacturer's protocols.

Tissues were homogenized with a Qiagen TissueLyser II (Hilden, Germany) in $2 \mathrm{ml}$ tubes with a $5 \mathrm{~mm}$ bead at $22 \mathrm{~Hz}$ for 2 minutes. $\mathrm{S} 9$ fractions were prepared using TBS by centrifugation at $9000 \mathrm{~g}$ for 30 minutes at $4^{\circ} \mathrm{C}$. Western blot analysis was performed using $20 \mu \mathrm{g}$ of $\mathrm{S} 9$ fractions that were analyzed as described previously for the UGT-overexpressing cell lines. Loading variability was monitored by Coomassie blue staining. Gelcode Blue Stain Reagent was used to detect total protein for normalization by densitometry analysis using Image $\mathbf{J}$ software (https://imagej.nih.gov/ij/; National Institutes of Health, Bethesda, MD).

Glycosylation Assays and Analysis. To screen for glycosylation activity for both UGT3A enzymes, incubations were performed with alternative sugars using a method adapted from a previous study (Bushey et al., 2011). Microsomes (10-100 $\mu \mathrm{g}$ total protein) from either the UGT3A1- or UGT3A2-overexpressing HEK293 cell lines were incubated with alamethicin $(50 \mu \mathrm{g} / \mathrm{mg}$ total protein) for 15 minutes on ice. Glycosylation reactions were performed with $200-800 \mu \mathrm{M}$ substrate, $50 \mathrm{mM}$ Tris- $\mathrm{HCl}$ (pH 7.4), $10 \mathrm{mM} \mathrm{MgCl}_{2}$, and $4 \mathrm{mM}$ UDP-GlcNAc, UDP-Glc, or UDP-Xyl in a final reaction volume of $25 \mu \mathrm{l}$ at $37^{\circ} \mathrm{C}$ for 1.5 hours. Reactions were terminated by the addition of $25 \mu \mathrm{l}$ cold acetonitrile. Reaction mixtures were centrifuged for 10 minutes at $16,100 \mathrm{~g}$, and supernatants were collected for ultra-performance liquid chromatography analysis.

Glycoside metabolite formation was quantified using an ACQUITY UPLC System (Waters, Milford, MA) utilizing an ACQUITY UPLC BEH C18 column $(1.7 \mu \mathrm{m}, 2.1 \times 100 \mathrm{~mm}$; Waters $)$ at a constant temperature of $25^{\circ} \mathrm{C}$. Using a flow rate of $0.4 \mathrm{ml} / \mathrm{min}$, glycosides were eluted and separated from parent substrate using various gradients for different PAHs. For the glycoside of 1-OH-pyrene, the

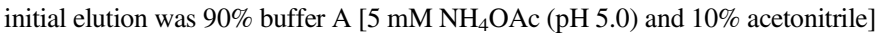
and $10 \%$ buffer $\mathrm{B}$ ( $100 \%$ acetonitrile) for 2 minutes, subsequent linear gradient to $75 \%$ B for 2 minutes, subsequent linear gradient to $100 \%$ B for 2 minutes, and return to the initial condition from 6 to 7.5 minutes. A similar gradient was used for other substrates, but the initial ratio of buffers A to B varied slightly. The substrates with an initial elution concentration of $85 \% \mathrm{~A}$ and $15 \% \mathrm{~B}$ were $1-\mathrm{OH}$ $\mathrm{B} a \mathrm{P}, 3-\mathrm{OH}-\mathrm{B} a \mathrm{P}, 7-\mathrm{OH}-\mathrm{B} a \mathrm{P}, 8-\mathrm{OH}-\mathrm{B} a \mathrm{P}, 9-\mathrm{OH}-\mathrm{B} a \mathrm{P}, \mathrm{B} a \mathrm{P}-7$, 8-diol, B $a \mathrm{P}-9,10-$ diol, DBalP-11,12-diol, and 5-MeC-1,2-diol; 1-naphthol was examined with an initial elution concentration of $80 \% \mathrm{~A}$ and $20 \% \mathrm{~B}$. The UV absorbance for each substrate and glycoside were as follows: 1-OH-pyrene and 1-naphthol were detected at $240 \mathrm{~nm}$; $\mathrm{B} a \mathrm{P}-7,8-\mathrm{diol}, \mathrm{B} a \mathrm{P}-9,10-$ diol, and 5-MeC-1,2-diol were detected at $254 \mathrm{~nm}$; and 1-OH-B $a \mathrm{P}, 3-\mathrm{OH}-\mathrm{B} a \mathrm{P}, 7-\mathrm{OH}-\mathrm{B} a \mathrm{P}, 8-\mathrm{OH}-\mathrm{B} a \mathrm{P}, 9-\mathrm{OH}-$ $\mathrm{B} a \mathrm{P}$, and $\mathrm{DB} a l \mathrm{P}-11,12-$ diol were detected at $305 \mathrm{~nm}$. If a metabolite peak was identified, kinetic analysis was performed for the enzyme against the active substrate. Kinetic analysis was performed for UGT3A-overexpressing microsomes (100 $\mu \mathrm{g}$ for UGT3A1; 0.20-75 $\mu \mathrm{g}$ for UGT3A2) using $0.25-2800 \mu \mathrm{M}$ substrate. For glycosylation rate determinations, total protein and incubation times for each substrate were optimized experimentally to ensure that substrate utilization was less than $10 \%$ and to maximize the levels of detection while in a linear range of glycoside formation. Reactions were terminated after 1.5 hours for UGT3A 1 and 45 minutes or 2 hours for UGT3A2 by the addition of $25 \mu$ cold acetonitrile.

The area under the curve for the substrate and glycoside peaks were determined using the MassLynx 4.1 software and quantified using the ratio of glycoside compared with unconjugated substrate. 1-OH-pyrene, a common UGT substrate and a known substrate for UGT3A1 and 3A2 (Mackenzie et al., 2008, MacKenzie et al., 2011), was used as a positive control for activity. Reactions with untransfected HEK293 cell microsomes, no substrate added, or substrate only, were used as negative controls. In addition, UGT2A1-overexpressing microsomes were used as a positive control for all substrates (Bushey et al., 2011). The metabolites were confirmed by sensitivity to glycosidases $(\beta-N$-acetylglucosaminidase for reactions with microsomal UGT3A1 protein and $\beta$-glucosidase and $\beta$-xylosidase for reactions with microsomal UGT3A2 protein) by incubating $2 \mu \mathrm{l}$ of glycosidase in a reconstituted $10 \mu \mathrm{l}$ reaction (with water) at $37^{\circ} \mathrm{C}$ overnight. Reactions were terminated by the addition of $12 \mu$ l cold acetonitrile and processed as described previously. Kinetic parameters $\left(K_{\mathrm{m}}\right.$ and $\left.V_{\max }\right)$ were calculated from triplicate experiments using GraphPad Prism 7.

Statistical Analysis. A two-tailed $t$ test was used to compare the kinetics $\left(K_{\mathrm{m}}\right.$, $V_{\max }$, and $\left.V_{\max } / K_{\mathrm{m}}\right)$ of glycoside formation for the UGT3A2-overexpressing HEK293 cell line for UDP-Xyl when comparing to UDP-Glc. A $P$ value of less than 0.05 was considered statistically significant.

\section{Results}

Expression of UGT3A Enzymes in Human Tissues. In the current study, UGT3A1 and UGT3A2 expression was analyzed in a comprehensive panel of aerodigestive tract tissues. As shown by western blots of UGT3A1- and UGT3A2-overexpressing cell lines, there was no crossreactivity of the UGT3A1 (Fig. 1A) or UGT3A2 (Fig. 1B) antibodies with any of the other UGTs tested. The molecular weight of both recombinant UGT3A proteins was approximately $53 \mathrm{kDa}$, as reported previously (Mackenzie et al., 2008, MacKenzie et al., 2011).

Representative western blots showed that both UGT3A1 and 3A2 were expressed in all tissues tested (Fig. 1, C and D, respectively). Densitometry analysis showed that the relative expression of UGT3A1 was highest in liver (used as the reference at 1.0), followed by tongue, jejunum, and larynx (approximately 0.30 for each) $>$ trachea $(0.20)>$ lung, breast, and colon (approximately 0.14 for each) $>$ tonsil and esophagus (approximately 0.040 for both) $>$ floor of mouth $(0.025)$ (Fig. 1E). The relative expression for UGT3A2 was highest in the floor of the mouth (used as the reference at 1.0), followed by trachea and larynx (approximately 0.70 for both) $>$ breast, lung, and tongue (approximately 0.60 for each) $>$ esophagus, tonsil, and colon (approximately 0.50 for each) $>$ jejunum $(0.30)>\operatorname{liver}(0.21)($ Fig. $1 \mathrm{~F})$.

Glycosylation of PAHs by UGT3A Enzymes. Microsomal protein from the UGT3A1- and UGT3A2-overexpressing HEK293 cell lines was used to screen for activity against the following PAHs: 1OH-pyrene, 1-naphthol, 1-OH-B $a \mathrm{P}, 3-\mathrm{OH}-\mathrm{B} a \mathrm{P}, 7-\mathrm{OH}-\mathrm{B} a \mathrm{P}, 8-\mathrm{OH}-$ $\mathrm{B} a \mathrm{P}$, 9-OH-B $a \mathrm{P}, \mathrm{B} a \mathrm{P}-7,8-d i o l, \mathrm{~B} a \mathrm{P}-9,10-$ diol, DBalP-11,12-diol, and 5-MeC-1,2-diol. In vitro glycosylation assays using UDP-GlcNAc as cosubstrate showed UGT3A1 activity against 1-OH-pyrene, a known UGT3A1 substrate (Meech and Mackenzie, 2010), to form the pyrenil-1-O-GlcNAc conjugate (retention time: 3.78 minutes) (Fig. 2A). UGT3A1-overexpressing microsomes also demonstrated 

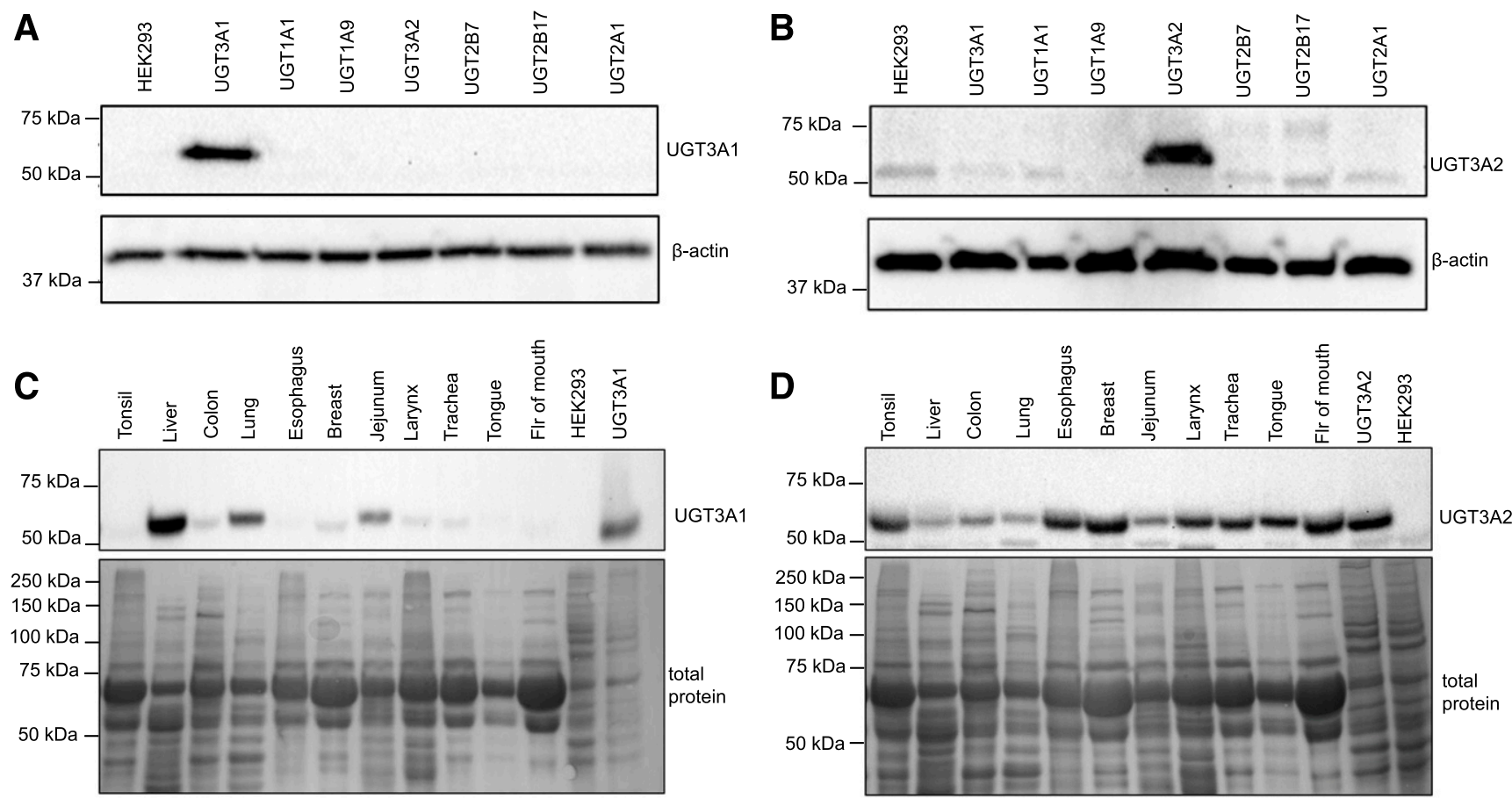

E

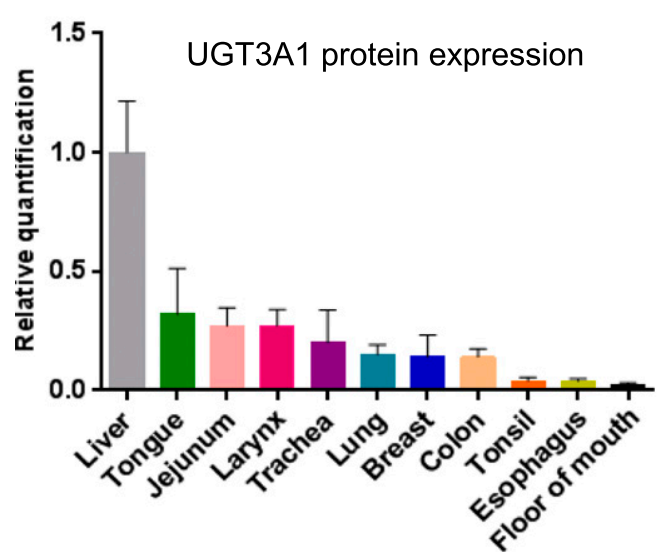

$\mathbf{F}$

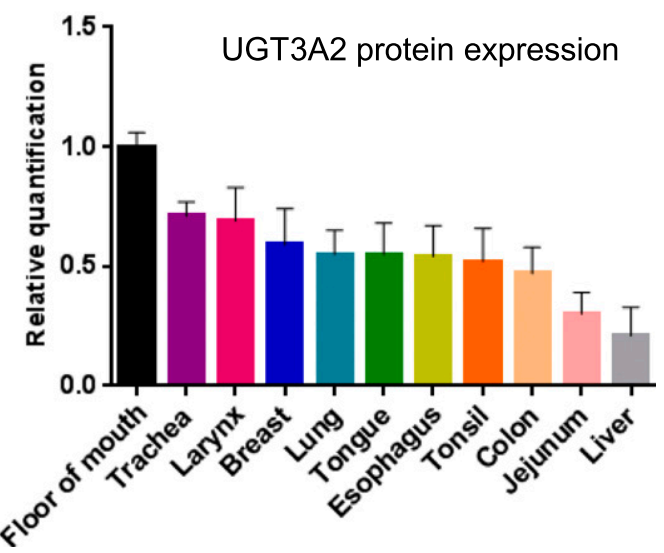

Fig. 1. Western blot analysis of UGT3A1 and 3A2 protein expression in HEK293 overexpressing cell lines and human tissues. (A) Antibody against UGT3A1 was analyzed for specificity for the UGT3A1-overexpressing HEK293 cell line, and possible crossreactivity with the empty HEK293 parent cell line and cell lines overexpressing UGT1A1, 1A9, 3A2, 2B7, 2B17, and 2A1 using total protein homogenate $(20 \mu \mathrm{g})$. $\beta$-Actin was used as a loading control. (B) Antibody against UGT3A2 was analyzed for specificity for the UGT3A2-overexpressing HEK293 cell line, and possible crossreactivity with empty HEK293 parent cell line and cell lines overexpressing UGT3A1, 1A1, $1 \mathrm{~A} 9,2 \mathrm{~A} 1,2 \mathrm{~B} 7$, and 2B17 using total protein homogenate $(20 \mu \mathrm{g})$. $\beta$-Actin was used as a loading control. (C) Representative western blot of UGT3A1 protein expression of S9 fractions of various human tissues ( $n=2-5$ specimens for each tissue site). The S9 fraction of UGT3A1-overexpressing HEK293 cells was used as a positive control, and the S9 fraction of the HEK293 parent cell line was used as a negative control. Total protein stain was used to normalize expression in tissues. (D) Representative western blot of UGT3A2 protein expression of S9 fraction in various human tissues $(n=2-5$ specimens for each tissue site). The S9 fraction of UGT3A2-overexpressing HEK293 cells was used as a positive control, and the S9 fraction of the HEK293 parent cell line was used as a negative control. Total protein stain was used to normalize expression in tissues. (E) Relative UGT3A1 protein expression was quantified by comparing protein levels in each tissue with the tissue exhibiting the highest UGT3A1 expression (i.e., liver). (F) Relative UGT3A2 protein expression was quantified by comparing protein levels in each tissue with the tissue exhibiting the highest UGT3A2 expression (i.e., floor of mouth). (E and F) Relative amounts are expressed as the mean \pm S.E. to account for the number of tissues analyzed in each group $(n=2-5$ specimens for each tissue site).

activity against 8-OH-BaP (Fig. 2B) and $\mathrm{B} a \mathrm{P}-9,10$-diol (Fig. 2C). Two GlcNAc conjugates were observed for $\mathrm{B} a \mathrm{P}-9,10$-diol (retention times: 3.28 and 3.34 minutes), likely representing $N$-acetylglucosaminides at the 9- and 10-diol positions. Detectable glycosylation activity for UGT3A1-overexpressing microsomes was not observed for any other PAH tested using up to $100 \mu \mathrm{g}$ microsomal protein. No glycosylation was observed for microsomes from the parent HEK293 cell line for 1$\mathrm{OH}-$ pyrene, 8-OH-B $a \mathrm{P}$, or $\mathrm{B} a \mathrm{P}-9,10$-diol using UDP-GlcNAc as cosubstrate (Fig. 2, A-C) or when using either UDP-Glc, UDP-Xyl, or UDP-GlcUA as cosubstrate (data not shown).
In vitro glycosylation assays with UGT3A2-overexpressing microsomes showed UGT3A2 activity against all of the PAHs tested using UDP-Glc as cosubstrate. In addition to 1-OH-pyrene, UGT3A2overexpressing microsomes exhibited high activity against the simple PAHs (1-OH-B $a \mathrm{P}, 3-\mathrm{OH}-\mathrm{B} a \mathrm{P}, 7-\mathrm{OH}-\mathrm{B} a \mathrm{P}$, and 9-OH-B $a \mathrm{P}$ ) to form glucoside metabolites with a range of retention times from 3.84 to 4.26 minutes (Fig. 3, A-C, for 1-OH-pyrene, 1-OH-BaP, and 9-OH$\mathrm{B} a \mathrm{P}$, respectively). More moderate activity was observed for UGT3A2overexpressing microsomes against 1-naphthol (data not shown). Less overall activity was observed for UGT3A2-overexpressing microsomes 
A

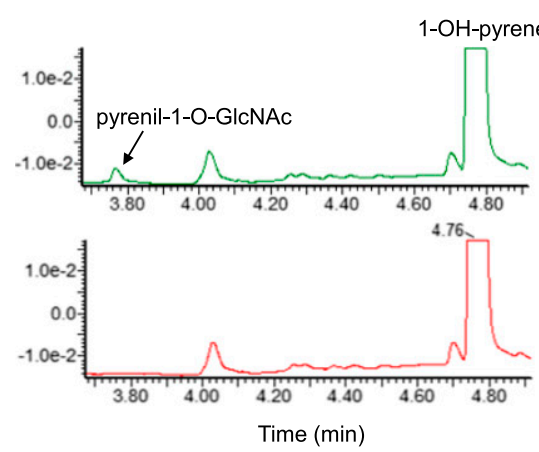

D

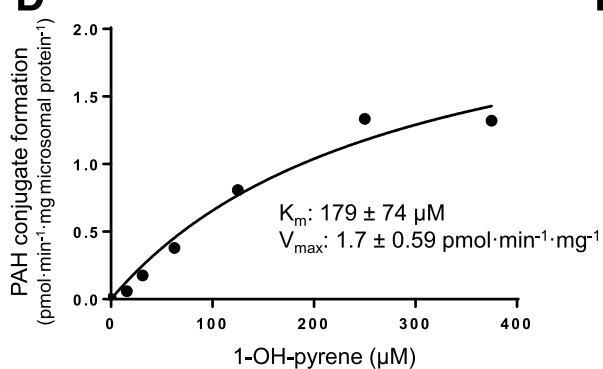

B

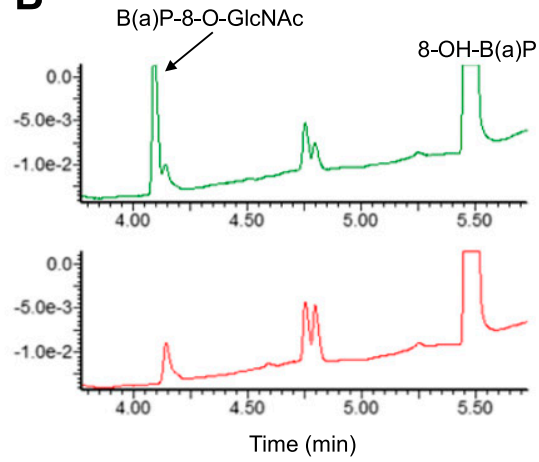

E

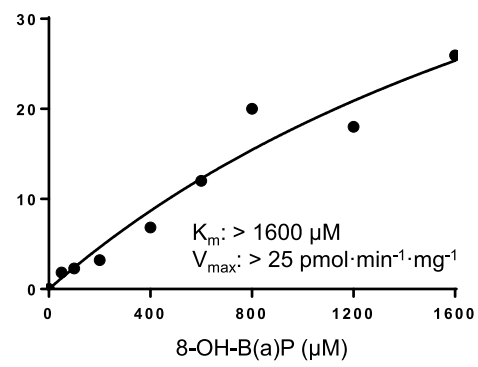

C

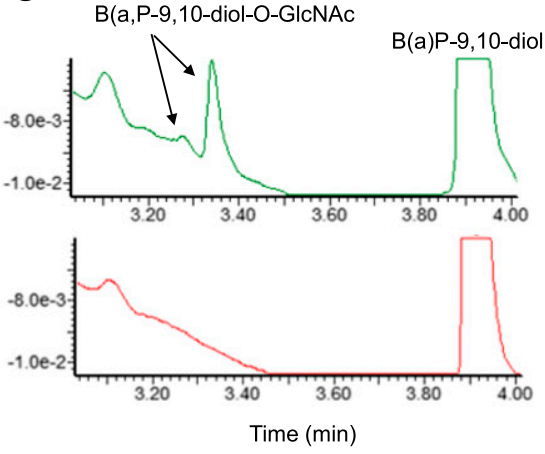

$\mathbf{F}$

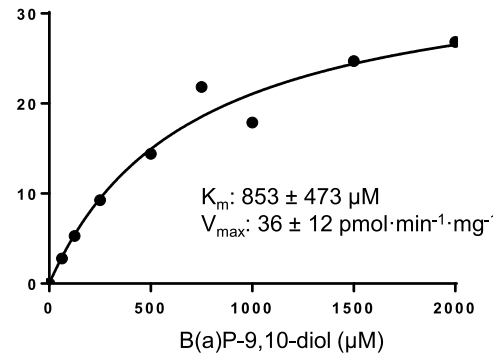

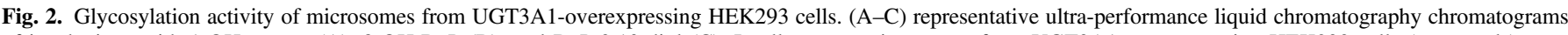

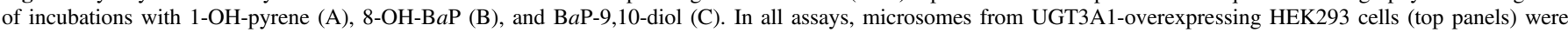

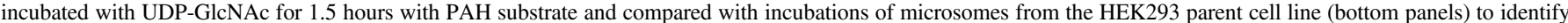

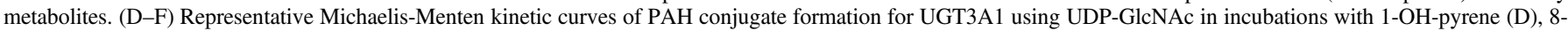
$\mathrm{OH}-\mathrm{B} a \mathrm{P}(\mathrm{E})$, and $\mathrm{B} a \mathrm{P}-9,10-\mathrm{diol}(\mathrm{F})$. Data are expressed as the mean \pm S.D. of three independent experiments.

against more complex PAHs including $\mathrm{B} a \mathrm{P}-7,8$-diol (conjugate retention time: 3.80 minutes) (Fig. 3D) and $\mathrm{B} a \mathrm{P}-9,10$-diol (two conjugates observed, retention times: 3.35 and 3.41 minutes) (Fig. 3E). Similar levels of activity were observed for UGT3A2-overexpressing microsomes against DBalP-11,12-diol (conjugate retention time: 4.16 minutes) (Fig. 3F) and 5-MeC-1,2-diol (data not shown). No glycosylation was observed for microsomes from the parent HEK293 cell line for all PAHs tested using UDP-Glc (Fig. 3), UDP-Xyl (Fig. 4), UDPGlcNAc (data not shown), or UDP-GlcUA (data not shown) as cosubstrates.

A similar pattern of activity was observed for UGT3A2-overepressing microsomes when using UDP-Xyl as the cosubstrate in in vitro glycosylation activity assays, with high activity observed against 1$\mathrm{OH}-$ pyrene, 1-OH-B $a \mathrm{P}, 3-\mathrm{OH}-\mathrm{B} a \mathrm{P}, 7-\mathrm{OH}-\mathrm{B} a \mathrm{P}$, and 9-OH-B $a \mathrm{P}$ [Fig. 4, $\mathrm{A}-\mathrm{C}$, for 1-OH-pyrene, 1-OH-B $a \mathrm{P}$, and 9-OH-B $a \mathrm{P}$, respectively]. Again, less overall activity was observed for UGT3A2-overexpressing microsomes against more complex PAHs, with peaks corresponding to xyloside conjugates observed for UGT3A2-overexpressing microsomes at 4.05 minutes for $\mathrm{B} a \mathrm{P}-7,8-\mathrm{diol}$ (Fig. 4D), 3.49 and 3.59 minutes for $\mathrm{B} a \mathrm{P}-9,10-$ diol (Fig. 4E), and 4.44 minutes for DBalP-11,12-diol (Fig. 4F). Glycosylated metabolites were confirmed by sensitivity to glycosidases, with cleavage of the sugar observed for 1-OH-pyrene, $1-\mathrm{OH}-\mathrm{B} a \mathrm{P}$, and $9-\mathrm{OH}-\mathrm{B} a \mathrm{P}$ after treatment with $\beta$-glucosidase (Supplemental Fig. 1, A-C) or $\beta$-xylosidase (Supplemental Fig. 1, D-F).

Kinetic Studies of PAHs by UGT3A Enzymes. After screening for UGT3A1 activity against all PAH substrates, kinetic parameters were determined for 1-OH-pyrene, 8-OH-B $a \mathrm{P}$, and $\mathrm{B} a \mathrm{P}-9,10-$ diol using UDP-GlcNAc as the cosubstrate, with representative MichaelisMenten kinetic curves shown in Fig. 2, D-F. Kinetic assays using the UGT3A1-overexpressing HEK293 cell microsomes with UDPGlcNAc exhibited the highest activity for $\mathrm{B} a \mathrm{P}-9,10-$ diol $\left(V_{\max } / K_{\mathrm{m}}=\right.$ $0.048 \pm 0.010 \mu \mathrm{l} \cdot \mathrm{min}^{-1} \cdot \mathrm{mg}^{-1}$ ) (Fig. 2F) followed by 1-OH-pyrene $\left(V_{\max } / K_{\mathrm{m}}=0.010 \pm 0.0019 \mu \mathrm{l} \cdot \mathrm{min}^{-1} \cdot \mathrm{mg}^{-1}\right)$ (Fig. 2D). Exact kinetic values could not be obtained for $8-\mathrm{OH}-\mathrm{B} a \mathrm{P}\left(K_{\mathrm{m}}>1600 \mu \mathrm{M}, V_{\max }>\right.$ $\left.25 \mathrm{pmol} \cdot \mathrm{min}^{-1} \cdot \mathrm{mg}^{-1}\right)$ since the rate of $\mathrm{B} a \mathrm{P}-8-\mathrm{O}-\mathrm{GlcNAc}$ formation did not reach saturation using up to $1600 \mu \mathrm{M}$ substrate (Fig. 2E).

After screening for activity against the PAH substrates, kinetic parameters were determined for UGT3A2 using UDP-Glc or UDP$\mathrm{Xyl}$ as cosubstrates. Representative Michaelis-Menten kinetic curves are shown for simple PAHs in Fig. 5, A-C and complex PAHs in Fig. 5, D-F using both cosubstrates. When using UDP-Glc as the cosubstrate, UGT3A2-overexpressing microsomes exhibited the highest activity for 1-OH-pyrene $\left(V_{\max } / K_{\mathrm{m}}=396 \pm 52 \mu \mathrm{l} \cdot \mathrm{min}^{-1} \cdot \mathrm{mg}^{-1}\right)$, with high levels of activity also observed for $3-\mathrm{OH}-\mathrm{B} a \mathrm{P}\left(V_{\max } / K_{\mathrm{m}}=238 \pm 51 \mu \mathrm{l} \cdot \mathrm{min}^{-1} \cdot \mathrm{mg}^{-1}\right)$ and 1-OH-B $a \mathrm{P}\left(V_{\max } / K_{\mathrm{m}}=202 \pm 54 \mu \mathrm{l} \cdot \mathrm{min}^{-1} \cdot \mathrm{mg}^{-1}\right)$ (Table 1). Slightly lower overall activity was observed for 9-OH-B $a \mathrm{P}\left(V_{\max } / K_{\mathrm{m}}=\right.$ $\left.84 \pm 4.7 \mu \mathrm{l} \cdot \mathrm{min}^{-1} \cdot \mathrm{mg}^{-1}\right)$ and $7-\mathrm{OH}-\mathrm{B} a \mathrm{P}\left(V_{\max } / K_{\mathrm{m}}=56 \pm 6.2 \mu 1 \cdot \mathrm{min}^{-1} \cdot \mathrm{mg}^{-1}\right)$. Lower levels of activity were observed for 1-naphthol $\left(V_{\max } / K_{\mathrm{m}}=\right.$ $\left.2.2 \pm 0.40 \mu \mathrm{l} \cdot \mathrm{min}^{-1} \cdot \mathrm{mg}^{-1}\right), \mathrm{DB} a \mathrm{P}-11,12-\operatorname{diol}\left(V_{\max } / K_{\mathrm{m}}=0.074 \pm\right.$ $\left.0.0058 \mu \mathrm{l} \cdot \mathrm{min}^{-1} \cdot \mathrm{mg}^{-1}\right), \quad \mathrm{B} a \mathrm{P}-7,8$-diol $\quad\left(V_{\max } / K_{\mathrm{m}}=0.034 \pm\right.$ $\left.0.0059 \mu \mathrm{l} \cdot \mathrm{min}^{-1} \cdot \mathrm{mg}^{-1}\right), \quad 5-\mathrm{MeC}-1,2-$ diol $\left(V_{\max } / K_{\mathrm{m}}=0.031 \pm\right.$ $\left.0.0047 \mu \mathrm{l} \cdot \mathrm{min}^{-1} \cdot \mathrm{mg}^{-1}\right)$, and $\mathrm{B} a \mathrm{P}-9,10-\operatorname{diol}\left(V_{\max } / K_{\mathrm{m}}=0.0087 \pm\right.$ $0.00069 \mu \mathrm{l} \cdot \mathrm{min}^{-1} \cdot \mathrm{mg}^{-1}$ ).

A similar pattern was observed for UGT3A2-overepressing microsomes when using UDP-Xyl as the cosubstrate. The highest level of activity was again observed against simple $\mathrm{PAHs}$ including 1-OH-pyrene $\left(V_{\max } / K_{\mathrm{m}}=840 \pm 254 \mu \mathrm{l} \cdot \mathrm{min}^{-1} \cdot \mathrm{mg}^{-1}\right)>3-\mathrm{OH}-\mathrm{B} a \mathrm{P}\left(V_{\max } / K_{\mathrm{m}}=\right.$ $\left.389 \pm 98 \mu \mathrm{l} \cdot \mathrm{min}^{-1} \cdot \mathrm{mg}^{-1}\right)>1-\mathrm{OH}-\mathrm{B} a \mathrm{P}\left(V_{\max } / K_{\mathrm{m}}=199 \pm 53 \mu \mathrm{l} \cdot \mathrm{min}^{-1} \cdot \mathrm{mg}^{-1}\right)$ $>9-\mathrm{OH}-\mathrm{B} a \mathrm{P}\left(V_{\max } / K_{\mathrm{m}}=129 \pm 10 \mu \mathrm{l} \cdot \mathrm{min}^{-1} \cdot \mathrm{mg}^{-1}\right)>7-\mathrm{OH}-\mathrm{B} a \mathrm{P}$ $\left(V_{\max } / K_{\mathrm{m}}=80 \pm 26 \mu \mathrm{l} \cdot \mathrm{min}^{-1} \cdot \mathrm{mg}^{-1}\right)>1$-naphthol $\left(V_{\max } / K_{\mathrm{m}}=3.54 \pm\right.$ $0.28 \mu \mathrm{l} \cdot \mathrm{min}^{-1} \cdot \mathrm{mg}^{-1}$ ) (Table 1$)$. Less overall activity was observed for the complex PAHs, with the highest level of activity observed for $\mathrm{B} a \mathrm{P}$ 7,8-diol $\left(V_{\max } / K_{\mathrm{m}}=0.11 \pm 0.011 \mu \mathrm{l} \cdot \mathrm{min}^{-1} \cdot \mathrm{mg}^{-1}\right)$, followed by $\mathrm{DB} a \mathrm{lP}-11,12-$ diol $\left(V_{\max } / K_{\mathrm{m}}=0.051 \pm 0.0015 \mu \mathrm{l} \cdot \mathrm{min}^{-1} \cdot \mathrm{mg}^{-1}\right)>$ $\mathrm{B} a \mathrm{P}-9,10-$ diol $\left(V_{\max } / K_{\mathrm{m}}=0.038 \pm 0.010 \mu \mathrm{l} \cdot \mathrm{min}^{-1} \cdot \mathrm{mg}^{-1}\right)>5-\mathrm{MeC}-$ 1,2 -diol $\left(V_{\max } / K_{\mathrm{m}}=0.020 \pm 0.0041 \mu \mathrm{l} \cdot \mathrm{min}^{-1} \cdot \mathrm{mg}^{-1}\right)$. 
A

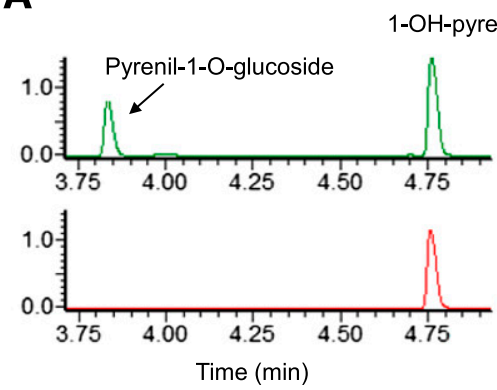

D

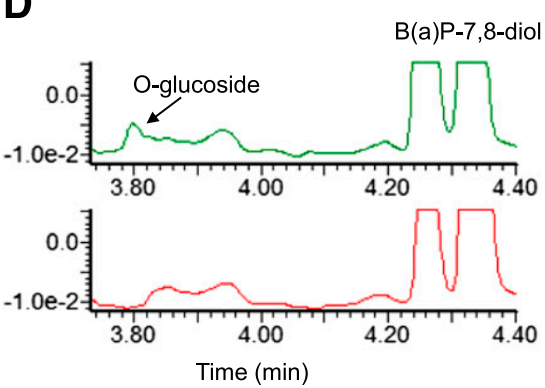

B
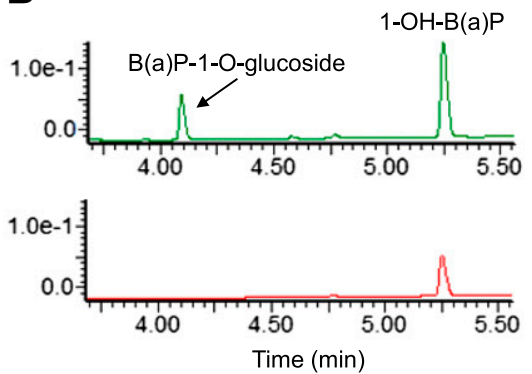

E
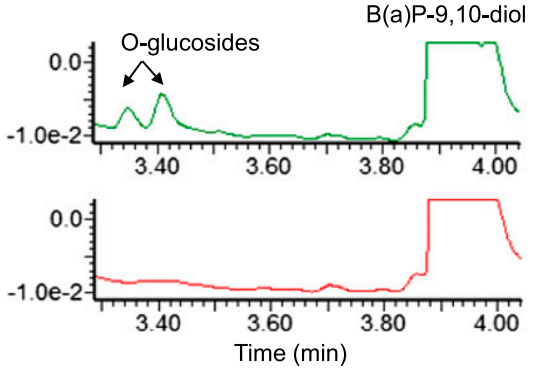

C
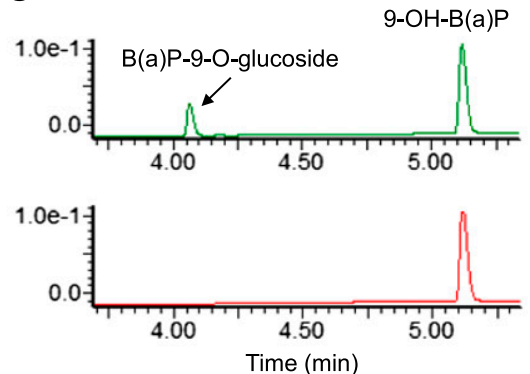

$\mathbf{F}$

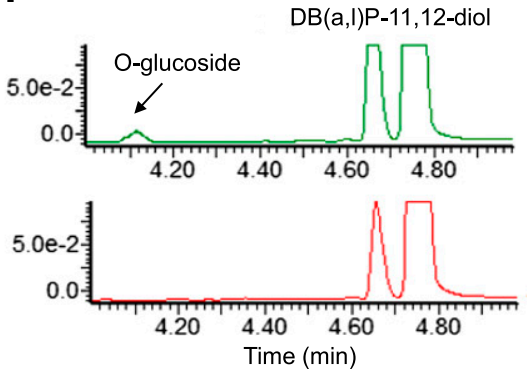

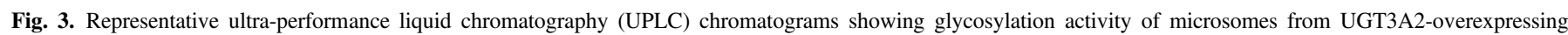

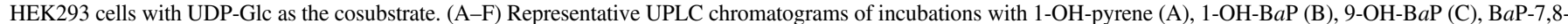

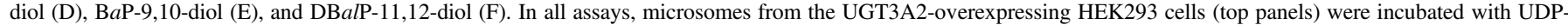
Glc for 1.5 hours with PAH substrate and compared with incubations of microsomes from the HEK293 parent cell line (bottom panels) to identify metabolites.

Except for 1-naphthol, the $K_{\mathrm{m}}$ value was at least an order of magnitude lower for the simple PAHs compared with the more complex PAHs, reaching 379-fold lower for 1-OH-pyrene compared with 5-MeC-1,2diol when using UDP-Glc as the cosubstrate, and 140-fold lower for 1$\mathrm{OH}-$ pyrene compared with $\mathrm{B} a \mathrm{P}-7,8$-diol when using UDP-Xyl as the cosubstrate. A significantly $(P<0.05)$ higher level of activity $\left(V_{\max } / K_{\mathrm{m}}\right)$ was observed for UGT3A2-overexpressing microsomes with UDP$\mathrm{Xyl}$ as the cosubstrate compared with assays with UDP-Glc as the cosubstrate for 1-naphthol, 9-OH-B $a \mathrm{P}, \mathrm{B} a \mathrm{P}-7,8-d i o l, \mathrm{~B} a \mathrm{P}-9,10-$ diol, and $\mathrm{DB} a l \mathrm{P}-11,12-$ diol, with the UDP-Xyl/UDP-Glc $V_{\max } / K_{\mathrm{m}}$ ratio reaching up to 4.4-fold for $\mathrm{B} a \mathrm{P}-9,10$-diol (Table 1).

\section{Discussion}

The role of the UGT3A subfamily in carcinogen metabolism has been understudied when compared with members of the UGT1A, 2A, and 2B
A
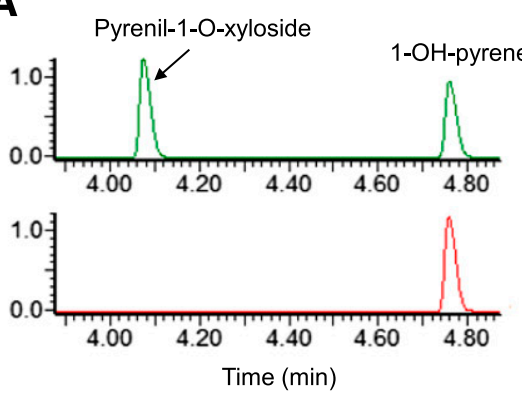

D
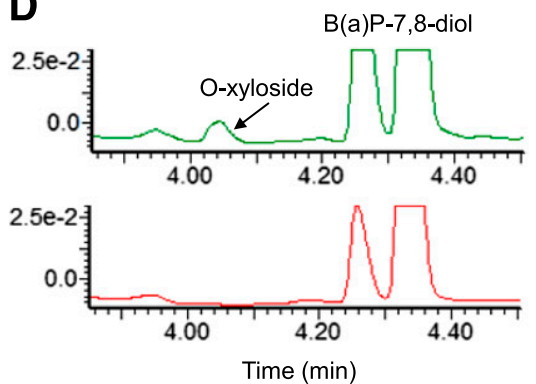

B

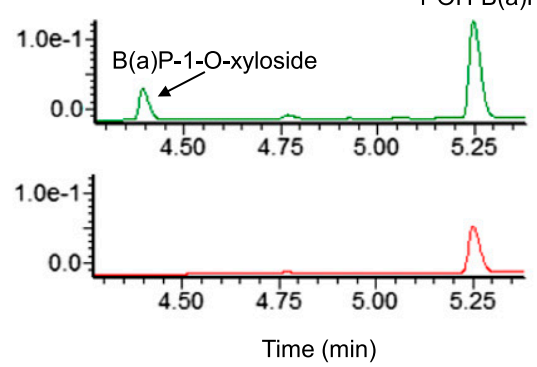

E

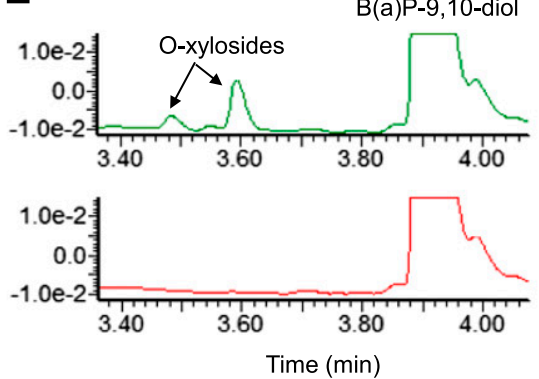

C

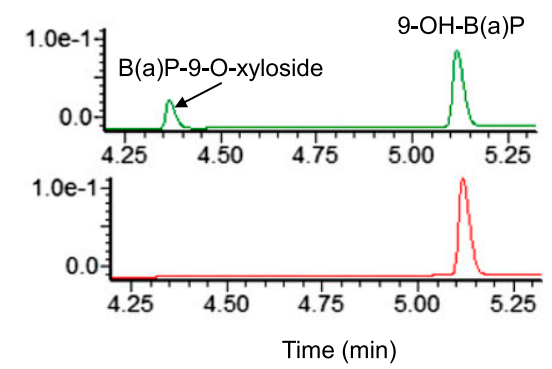

$\mathbf{F}$
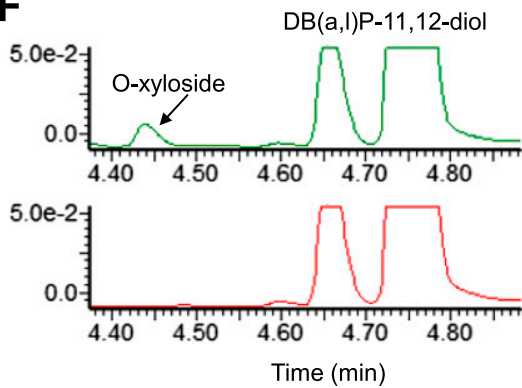

Fig. 4. Representative ultra-performance liquid chromatography (UPLC) chromatograms showing glycosylation activity of microsomes from UGT3A2-overexpressing HEK293 cells with UDP-Xyl as the cosubstrate. (A-F) Representative UPLC chromatograms of incubations with 1-OH-pyrene (A), 1-OH-B $a$ P (B), 9-OH-B $a$ P (C), B $a$ P-7,8diol (D), BaP-9,10-diol (E), and DBalP-11,12-diol (F). In all assays, microsomes from the UGT3A2-overexpressing HEK293 cells (top panels) were incubated with UDPXyl for 1.5 hours with PAH substrate and compared with incubations of microsomes from the HEK293 parent cell line (bottom panels) to identify metabolites. 


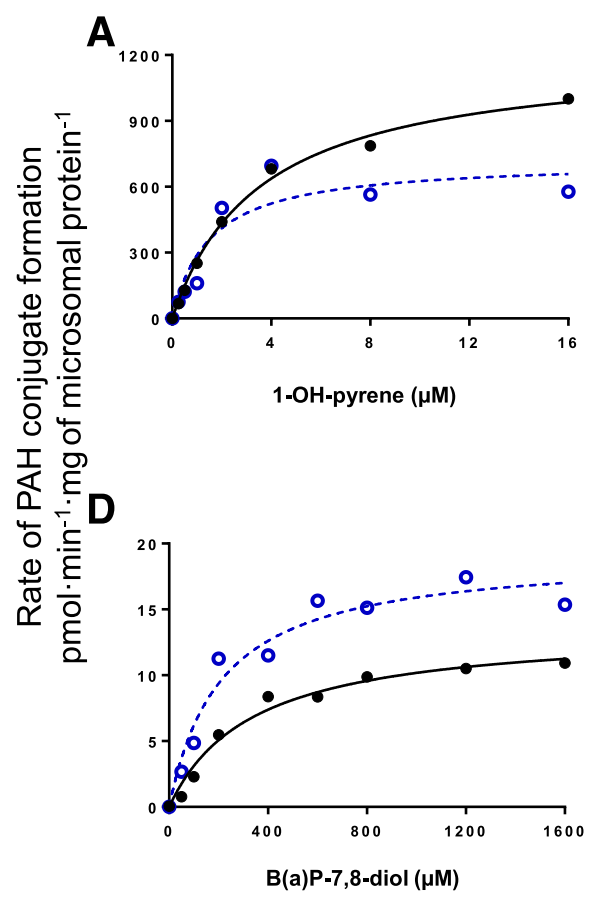

B

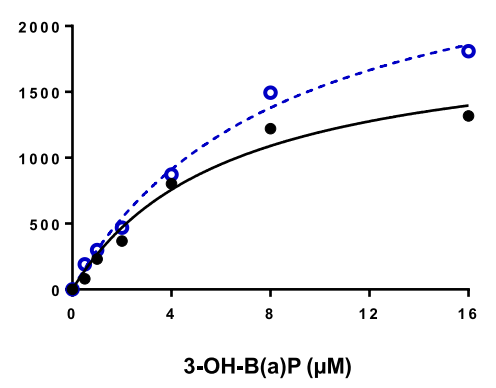

E

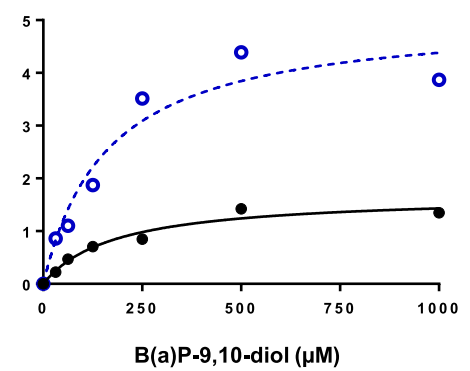

C

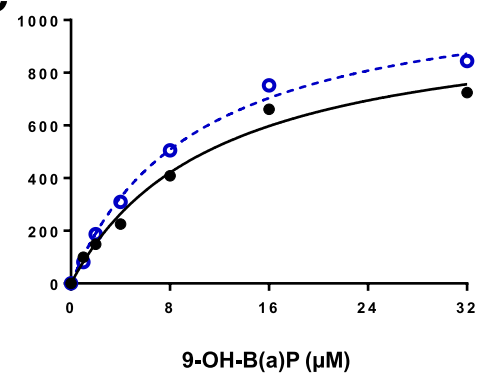

$\mathbf{F}$

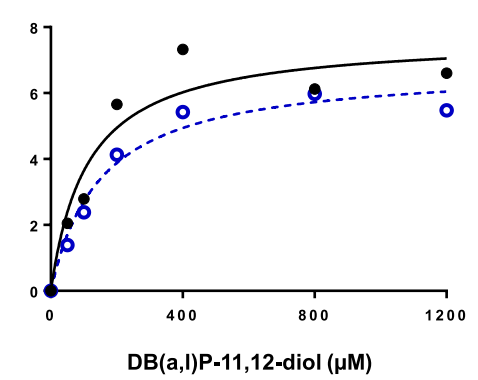

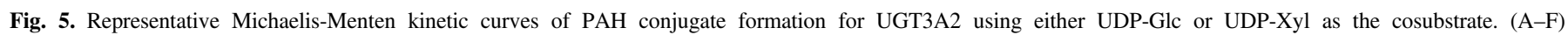

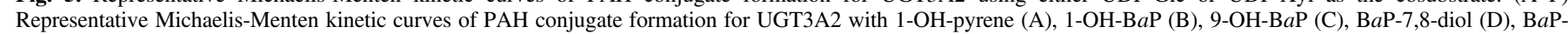

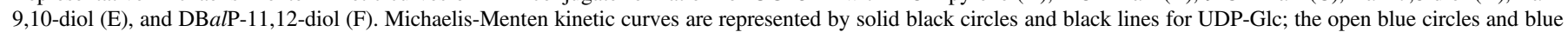
dashed lines represent UDP-Xyl.

subfamilies, with UGT3A1 and 3A2 having previously been shown to exhibit activity against the simple PAHs 1-naphthol and 1-OHpyrene (Mackenzie et al., 2008, MacKenzie et al., 2011; Meech and Mackenzie, 2010; Meech et al., 2012). In the present study, UGT3A1 was confirmed to exhibit activity against $1-\mathrm{OH}-$ pyrene, and it also exhibited glycosylation activity against 8-OH-B $a \mathrm{P}$ and $\mathrm{B} a \mathrm{P}-9,10-$ diol. However, no detectable activity was observed for UGT3A1 against any other PAH tested. While UGT3A1 exhibited low activity against the three PAHs, this activity was approximately 5-fold higher (i.e., $V_{\max } / K_{\mathrm{m}}$ ) against the more complex $\mathrm{PAH}, \mathrm{B} a \mathrm{P}-9,10-$ diol than against 1-OH-pyrene.

A different pattern was observed for UGT3A2, with relatively high glycosylation activity against all of the PAHs tested when either UDPGlc or UDP-Xyl was used as the cosubstrate. The activity of UGT3A2 was higher against the simple PAHs, with the $V_{\max } / K_{\mathrm{m}}$ ratios ranging from 644- to 12,774-fold higher for 1-OH-pyrene, 1-OH-BaP, 3-OH$\mathrm{B} a \mathrm{P}, 7-\mathrm{OH}-\mathrm{B} a \mathrm{P}$, and 9-OH-B $a \mathrm{P}$ compared with the more complex PAHs including $\mathrm{B} a \mathrm{P}-7,8-d i o l, \mathrm{~B} a \mathrm{P}-9,10-d i o l, \mathrm{DB} a l \mathrm{P}-11$,12-diol, and 5MeC-1,2-diol when UDP-Glc was used as the cosubstrate, and 727- to 42,000-fold higher when UDP-Xyl was used as the cosubstrate. The only simple PAH that UGT3A2 exhibited modest activity against was 1naphthol, which exhibited a $V_{\max } / K_{\mathrm{m}}$ ratio that was 23 - to 25 -fold lower with either UDP-Glc or UDP-Xyl as the cosubstrate than that observed for 7-OH-B $a$ P, the simple PAH against which UGT3A2 exhibited the next lowest activity.

UGT3A2 using UDP-Xyl as the cosubstrate exhibited approximately equivalent or slightly lower $K_{\mathrm{m}}$ values than when using UDP-Glc as the cosubstrate against all PAHs tested, except for DBalP-11,12-diol. Similarly, the $V_{\text {max }} / K_{\mathrm{m}}$ ratios observed for UGT3A2 with UDP-Xyl as the cosubstrate were similar to or higher than assays with UDP-Glc as

TABLE 1

Kinetic analysis of UGT3A2 activity against PAH substrates using alternative sugars as cosubstrates ${ }^{a}$

\begin{tabular}{|c|c|c|c|c|c|c|c|c|}
\hline \multirow[b]{2}{*}{ Substrate } & \multicolumn{3}{|c|}{ UDP-Glucose } & \multicolumn{3}{|c|}{ UDP-Xylose } & \multicolumn{2}{|c|}{ UDP-Xyl/UDP-Glc } \\
\hline & $\begin{array}{l}K_{\mathrm{m}} \\
\mu \mathrm{M}\end{array}$ & $\begin{array}{c}V_{\max } \\
\mathrm{pmol} \cdot \mathrm{min}^{-1} \cdot \mathrm{mg}^{-1}\end{array}$ & $\begin{array}{c}V_{\max } / K_{\mathrm{m}} \\
\mu \mathrm{l} \cdot \mathrm{min}^{-1} \cdot \mathrm{mg}^{-1}\end{array}$ & $\begin{array}{l}K_{\mathrm{m}} \\
\mu \mathrm{M}\end{array}$ & $\begin{array}{c}V_{\max } \\
\mathrm{pmol} \cdot \mathrm{min}^{-1} \cdot \mathrm{mg}^{-1}\end{array}$ & $\begin{array}{c}V_{\max } / K_{\mathrm{m}} \\
\mu \mathrm{l} \cdot \mathrm{min}^{-1} \cdot \mathrm{mg}^{-1}\end{array}$ & $K_{\mathrm{m}}$ Ratio & $\begin{array}{c}V_{\max } / K_{\mathrm{m}} \\
\text { Ratio }\end{array}$ \\
\hline 1-Naphthol & $225 \pm 31$ & $489 \pm 24$ & $2.2 \pm 0.40$ & $129 \pm 32 *$ & $453 \pm 58$ & $3.5 \pm 0.28 *$ & 0.57 & 1.6 \\
\hline 1-OH-pyrene & $3.3 \pm 0.18$ & $1305 \pm 118$ & $396 \pm 52$ & $1.2 \pm 0.19^{*}$ & $998 \pm 204$ & $840 \pm 254$ & 0.36 & 2.1 \\
\hline 1-OH-benzo $(a)$ pyrene & $11 \pm 2.4$ & $2035 \pm 333$ & $202 \pm 54$ & $6.1 \pm 1.5$ & $1135 \pm 117^{*}$ & $199 \pm 53$ & 0.55 & 0.98 \\
\hline 3-OH-benzo $(a)$ pyrene & $7.5 \pm 0.93$ & $1734 \pm 181$ & $238 \pm 51$ & $7.2 \pm 2.9$ & $2525 \pm 599$ & $389 \pm 98$ & 0.96 & 1.6 \\
\hline 7-OH-benzo $(a)$ pyrene & $7.8 \pm 1.9$ & $430 \pm 67$ & $56 \pm 6.2$ & $8.5 \pm 0.53$ & $683 \pm 227$ & $80 \pm 26$ & 1.1 & 1.4 \\
\hline 9-OH-benzo $(a)$ pyrene & $12 \pm 0.55$ & $984 \pm 85$ & $84 \pm 4.7$ & $9.6 \pm 0.87 *$ & $1227 \pm 107$ & $129 \pm 10^{*}$ & 0.80 & 1.5 \\
\hline $\operatorname{Benzo}(a)$ pyrene-7,8-diol & $397 \pm 67$ & $13 \pm 0.51$ & $0.034 \pm 0.0059$ & $168 \pm 30^{*}$ & $18 \pm 1.2 *$ & $0.11 \pm 0.011 *$ & 0.42 & 3.2 \\
\hline $\operatorname{Benzo}(a)$ pyrene-9,10-diol & $190 \pm 16$ & $1.6 \pm 0.039$ & $0.0087 \pm 0.00069$ & $120 \pm 36$ & $4.3 \pm 0.57 *$ & $0.038 \pm 0.010^{*}$ & 0.63 & 4.4 \\
\hline $\operatorname{Dibenzo}(a, l)$ pyrene-11,12-diol & $96 \pm 8.3$ & $7.1 \pm 0.44$ & $0.074 \pm 0.0058$ & $143 \pm 6.8^{*}$ & $7.3 \pm 0.33$ & $0.051 \pm 0.0015^{*}$ & 1.5 & 0.69 \\
\hline 5-Methylchrysene-1,2-diol & $1250 \pm 319$ & $37 \pm 4.8$ & $0.031 \pm 0.0047$ & $124 \pm 6.8^{*}$ & $2.5 \pm 0.72 *$ & $0.020 \pm 0.0041$ & 0.099 & 0.65 \\
\hline
\end{tabular}

${ }^{a}$ Data are expressed as milligrams of total microsomal protein. The $K_{\mathrm{m}}, V_{\max }$, and $V_{\max } / K_{\mathrm{m}}$ values represent the mean \pm S.D. of three independent experiments.

$* P<0.05$ vs. corresponding value for UGT3A2-overexpressing microsomes using UDP-Glc as the cosubstrate. 
the cosubstrate. These data suggest that both sugars may be used equally efficiently by UGT3A2 for the conjugation of PAHs.

In the present study, modest relative expression was observed for UGT3A1 protein in aerodigestive tract tissues including tongue, lung, larynx, jejunum, trachea, and colon. The expression observed for UGT3A1 protein in human lung in the present study contrasts with the lack of UGT3A1 mRNA expression found in human lung in a previous study (Mackenzie et al., 2008). Relatively low UGT3A1 protein expression was observed in several other aerodigestive tract tissues including tonsil, esophagus, and floor of mouth. The relatively high expression of UGT3A1 found in human liver in the present study confirms the relatively high hepatic expression found for UGT3A1 mRNA in a previous study (Mackenzie et al., 2008).

Relatively high expression of UGT3A2 protein was observed in all aerodigestive tract tissues examined in the present study, with the highest expression observed in floor of mouth, trachea, larynx and tongue. The lowest relative expression of UGT3A2 protein was observed in human liver. This pattern was similar to the higher levels of UGT3A2 mRNA detected in trachea, lung, and colon than observed in liver in a previous study (MacKenzie et al., 2011). However, while UGT3A2 was found to be expressed in both liver and esophagus in the present study, UGT3A2 mRNA was not detected in either tissue in previous studies, potentially due to issues involving mRNA quality, lack of homogeneity between different tissue specimens, or the sensitivity of methods used for the different studies (MacKenzie et al., 2011).

Large differences in expression were observed between specimens for several tissue sites in this study. While this could be due to interindividual expression differences, which could potentially play a role in susceptibility to PAH-induced carcinogenesis, this could also be due to differences in cell composition between samples. For example, the 188-fold range in UGT3A1 expression for breast could be due to composition differences in epithelial and stromal cells, collagen, and fat (Boyd et al., 2010). Further studies using laser-dissected specimens will be required to better analyze this possibility.

UDP sugars are used in glycosylation reactions in the lumen of the endoplasmic reticulum and Golgi apparatus, but in addition they can also be used to form proteoglycans and glycoproteins and participate in cell signal transduction, protein targeting, intercellular communication, and recognition of pathogens (Bertozzi and Kiessling, 2001; Arase et al., 2009; Lazarowski and Harden, 2015). While differences in tissue or circulating UDP-sugar concentrations could potentially affect the activities of the different UGT enzymes against PAHs and other substrates, only limited studies have reported on the concentrations of UDP sugars in humans. UDP-Glc is converted by UDP-Glc-6-dehydrogenase to UDP-GlcUA, which can then be converted to UDP-Xyl by UDP-glucuronate decarboxylase (Harper and Bar-Peled, 2002). UDP-Xyl potentially inhibits UDP-Glc-6-dehydrogenase, which could affect the conversion of UDP-Glc to UDP-GlcUA in some tissues (Gainey and Phelps, 1972). UDP-Glc and UDP-GlcNAc exhibit higher concentrations than UDP-GlcUA in normal human breast tissue, with all UDP sugars increasing in concentration in breast cancer tissue (Oikari et al., 2018). Higher concentrations were observed for UDP-Glc than for UDP-Xyl in several animal tissues (Hardingham and Phelps, 1968; Handley and Phelps, 1972). An additional study reported levels of UDPGlc $(73 \mu \mathrm{M})>$ UDP-GlcUA $(28 \mu \mathrm{M})>$ UDP-galactose $(24 \mu \mathrm{M})>$ UDP-Xyl $(7.0 \mu \mathrm{M})$ in sheep nasal septum cartilage (Gainey and Phelps, 1972).

Previous studies have examined UGT2B expression in lung, showing that UGT2B11 and 2B17 exhibit the highest levels of expression, accounting for $49 \%$ and $30 \%$ of total lung UGT2B expression, respectively (Jones and Lazarus, 2014). Other studies suggested that UGT1A6 exhibited the highest level of expression in lung of any UGT enzyme, accounting for $39 \%$ of total UGT expression, with UGT1A1, $1 \mathrm{~A} 8$, and $2 \mathrm{~A} 1$ also accounting for $10 \%-25 \%$ of total lung expression (Nishimura and Naito, 2006). The UGTs that have shown some level of expression in lung that exhibit PAH activity are 1A1, 1A4, 1A5, 1A6, 1A9, 1A10, 2A1, 2A3, 2B7, 2B15, and 2B17, with 1A4 and 1A5 only shown to exhibit activity against 1-OH-pyrene (Jin et al., 1993; Münzel et al., 1996; Fang et al., 2002; Uchaipichat et al., 2004; Finel et al., 2005; Luukkanen et al., 2005; Dellinger et al., 2006; Nishimura and Naito, 2006; Nakamura et al., 2008; Itäaho et al., 2010; Bushey et al., 2011, 2013; Olson et al., 2011; Jones and Lazarus, 2014). Of these, UGT1A10 and 2A1 exhibited some of the lowest $K_{\mathrm{m}}$ values against PAHs (Dellinger et al., 2006; Bushey et al., 2011). UGT3A2-mediated glycosylation with UDP-Xyl exhibited lower or similar $K_{\mathrm{m}}$ values than these UGTs against many of the PAHs tested in the present study. A 9fold lower $K_{\mathrm{m}}$ value $(1.2 \mu \mathrm{M})$ for 1-OH-pyrene and a 4-fold lower $K_{\mathrm{m}}$ value $(9.6 \mu \mathrm{M})$ for $9-\mathrm{OH}-\mathrm{B} a \mathrm{P}$ were observed for UGT3A2 with UDP$\mathrm{Xyl}$ as the cosubstrate than that observed for UGT1A10 with UDPGlcUA as the cosubstrate (11 and $38 \mu \mathrm{M}$, respectively) (Dellinger et al., 2006). UGT3A2 also exhibited comparable $K_{\mathrm{m}}$ values for 3-OH-B $a \mathrm{P}$ (7.2 $\mu \mathrm{M}$ vs. $9.7 \mu \mathrm{M}), 7-\mathrm{OH}-\mathrm{B} a \mathrm{P}(8.5 \mu \mathrm{M}$ vs. $9.8 \mu \mathrm{M})$, and $\mathrm{B} a \mathrm{P}-7,8-$ diol (168 $\mu \mathrm{M}$ vs. $183-189 \mu \mathrm{M})$ compared with that observed previously for UGT1A10 (Fang et al., 2002; Dellinger et al., 2006). Similarly, the $K_{\mathrm{m}}$ values for UGT3A2-mediated glycosylation of $1-\mathrm{OH}-\mathrm{B} a \mathrm{P}$ and 5-MeC-1,2-diol with UDP-Xyl as the cosubstrate were 40- and 2.2-fold lower than that observed previously for UGT2A1 with UDP-GlcUA as the cosubstrate $(6.1 \mu \mathrm{M}$ vs. $247 \mu \mathrm{M}$ and $124 \mu \mathrm{M}$ vs. $270 \mu \mathrm{M}$, respectively) (Bushey et al., 2011). With UDP-Glc as the cosubstrate, the $K_{\mathrm{m}}$ value was lower for UGT3A2 for five PAHs when compared with other UGTs (using UDP-GlcUA as the cosubstrate), including 1$\mathrm{OH}-$ pyrene, 1-OH-B $a \mathrm{P}, 3-\mathrm{OH}-\mathrm{B} a \mathrm{P}, 7-\mathrm{OH}-\mathrm{B} a \mathrm{P}$, and 9-OH-B $a \mathrm{P}$ (Dellinger et al., 2006; Bushey et al., 2011).

Of all of the UGT enzymes, previous studies had shown that UGT1A10 exhibited the lowest $K_{\mathrm{m}}$ values against PAHs, and these values were in general very comparable to that observed for UGT3A2 in the present study. UGT1A10, like UGT3A2, is well expressed in a variety of aerodigestive tract tissues, suggesting that both UGT3A2 and 1A10 may be important enzymes for the detoxification of PAHs in these tissues (Mojarrabi and Mackenzie, 1998; Strassburg et al., 1999; Zheng et al., 2002; Dellinger et al., 2006; Nakamura et al., 2008). However, UGT3A2 is well expressed in lung while only one study has shown UGT1A10 to be expressed in lung (Dellinger et al., 2006). The other UGT enzyme that is well expressed in lung and exhibits relatively high glycosylating activity against PAHs is UGT2A1 (Bushey et al., 2011). Therefore, both UGT3A2 and 2A1 may be important in the detoxification of PAHs in lung.

In summary, UGT3A1 and 3A2 were shown be expressed in all of the aerodigestive tract tissues tested. UGT3A2 was significantly more active than UGT3A1 against all PAHs tested and exhibited the lowest $K_{\mathrm{m}}$ values against seven of the 10 PAHs tested in this study compared with that observed in previous studies for other UGTs. This high level of activity was observed when using either UDP-Glc or UDP-Xyl as the cosubstrate. These data suggest that UGT3A2 plays an important role in the detoxification of PAHs in target tissues like tissues of the aerodigestive tract. These data also suggest that PAHs could potentially be detoxified by various UGT enzymes using different cosubstrates.

\section{Authorship Contributions}

Participated in research design: Vergara, Watson, Chen, Lazarus.

Conducted experiments: Vergara.

Performed data analysis: Vergara, Watson, Chen, Lazarus.

Wrote or contributed to the writing of the manuscript: Vergara, Watson, Chen, Lazarus. 


\section{References}

Arase T, Uchida H, Kajitani T, Ono M, Tamaki K, Oda H, Nishikawa S, Kagami M, Nagashima T, Masuda H, et al. (2009) The UDP-glucose receptor P2RY14 triggers innate mucosal immunity in the female reproductive tract by inducing IL-8. J Immunol 182:7074-7084.

Bertozzi CR and Kiessling LL (2001) Chemical glycobiology. Science 291:2357-2364.

Boyd NF, Martin LJ, Bronskill M, Yaffe MJ, Duric N, and Minkin S (2010) Breast tissue composition and susceptibility to breast cancer. J Natl Cancer Inst 102:1224-1237.

Bushey RT, Chen G, Blevins-Primeau AS, Krzeminski J, Amin S, and Lazarus P (2011) Characterization of UDP-glucuronosyltransferase 2A1 (UGT2A1) variants and their potential role in tobacco carcinogenesis. Pharmacogenet Genomics 21:55-65.

Bushey RT, Dluzen DF, and Lazarus P (2013) Importance of UDP-glucuronosyltransferases 2A2 and 2A3 in tobacco carcinogen metabolism. Drug Metab Dispos 41:170-179.

Choi H, Harrison R, Komulainen H, and Delgado Saborit JM (2010) WHO Guidelines for Indoor Air Quality: Selected Pollutants (PAHs). 289-345.

Dellinger RW, Chen G, Blevins-Primeau AS, Krzeminski J, Amin S, and Lazarus P (2007) Glucuronidation of PhIP and N-OH-PhIP by UDP-glucuronosyltransferase 1A10. Carcinogenesis 28:2412-2418.

Dellinger RW, Fang JL, Chen G, Weinberg R, and Lazarus P (2006) Importance of UDPglucuronosyltransferase 1A10 (UGT1A10) in the detoxification of polycyclic aromatic hydrocarbons: decreased glucuronidative activity of the UGT1A10 ${ }^{139 \text { Lys }}$ isoform. Drug Metab Dispos 34:943-949.

Ewa B and Danuta MS (2017) Polycyclic aromatic hydrocarbons and PAH-related DNA adducts. $J$ Appl Genet 58:321-330.

Fang JL, Beland FA, Doerge DR, Wiener D, Guillemette C, Marques MM, and Lazarus P (2002) Characterization of benzo $(a)$ pyrene-trans-7,8-dihydrodiol glucuronidation by human tissue microsomes and overexpressed UDP-glucuronosyltransferase enzymes. Cancer Res 62:1978-1986.

Finel M, Li X, Gardner-Stephen D, Bratton S, Mackenzie PI, and Radominska-Pandya A (2005) Human UDP-glucuronosyltransferase 1A5: identification, expression, and activity. J Pharmacol Exp Ther 315:1143-1149.

Gainey PA and Phelps CF (1972) Uridine diphosphate glucuronic acid production and utilization in various tissues actively synthesizing glycosaminoglycans. Biochem J 128:215-227.

Gao P, da Silva E, Hou L, Denslow ND, Xiang P, and Ma LQ (2018) Human exposure to polycyclic aromatic hydrocarbons: metabolomics perspective. Environ Int 119:466-477.

Handley CJ and Phelps CF (1972) The concentrations of sugar nucleotides in bovine corneal epithelium and endothelium. Biochem J 127:911-912.

Hardingham TE and Phelps CF (1968) The tissue content and turnover rates of intermediates in the biosynthesis of glycosaminoglycans in young rat skin. Biochem $J$ 108:9-16.

Harper AD and Bar-Peled M (2002) Biosynthesis of UDP-xylose. Cloning and characterization of a novel Arabidopsis gene family, UXS, encoding soluble and putative membrane-bound UDPglucuronic acid decarboxylase isoforms. Plant Physiol 130:2188-2198.

Hecht SS (1999) Tobacco smoke carcinogens and lung cancer. J Natl Cancer Inst 91:1194-1210.

Hoffmann D, Hoffmann I, and El-Bayoumy K (2001) The less harmful cigarette: a controversial issue. A tribute to Ernst L. Wynder. Chem Res Toxicol 14:767-790.

Itäaho K, Laakkonen L, and Finel M (2010) How many and which amino acids are responsible for the large activity differences between the highly homologous UDP-glucuronosyltransferases (UGT) 1 A9 and UGT1A10? Drug Metab Dispos 38:687-696.

Jin CJ, Miners JO, Burchell B, and Mackenzie PI (1993) The glucuronidation of hydroxylated metabolites of benzo $[a]$ pyrene and 2-acetylaminofluorene by cDNA-expressed human UDPglucuronosyltransferases. Carcinogenesis 14:2637-2639.

Jones NR and Lazarus P (2014) UGT2B gene expression analysis in multiple tobacco carcinogentargeted tissues. Drug Metab Dispos 42:529-536.

Kim JH, Stansbury KH, Walker NJ, Trush MA, Strickland PT, and Sutter TR (1998) Metabolism of benzo[a]pyrene and benzo[a]pyrene-7,8-diol by human cytochrome P450 1B1. Carcinogenesis 19:1847-1853

Lazarowski ER and Harden TK (2015) UDP-sugars as extracellular signaling molecules: cellula and physiologic consequences of P2Y14 receptor activation. Mol Pharmacol 88:151-160.

Levin W, Buening MK, Wood AW, Chang RL, Kedzierski B, Thakker DR, Boyd DR, Gadaginamath GS, Armstrong RN, Yagi H, et al. (1980) An enantiomeric interaction in the metabolism and tumorigenicity of (+)- and (-)-benzo[a]pyrene 7,8-oxide. J Biol Chem 255:9067-9074.

Luukkanen L, Taskinen J, Kurkela M, Kostiainen R, Hirvonen J, and Finel M (2005) Kinetic characterization of the 1A subfamily of recombinant human UDP-glucuronosyltransferases. Drug Metab Dispos 33:1017-1026.

MacKenzie PI, Rogers A, Elliot DJ, Chau N, Hulin JA, Miners JO, and Meech R (2011) The novel UDP glycosyltransferase 3A2: cloning, catalytic properties, and tissue distribution. Mol Pharmacol 79:472-478.

Mackenzie PI, Rogers A, Treloar J, Jorgensen BR, Miners JO, and Meech R (2008) Identification of UDP glycosyltransferase 3A1 as a UDP $N$-acetylglucosaminyltransferase. J Biol Chem 283 $36205-36210$
Meech R and Mackenzie PI (2010) UGT3A: novel UDP-glycosyltransferases of the UGT superfamily. Drug Metab Rev 42:45-54.

Meech R, Miners JO, Lewis BC, and Mackenzie PI (2012) The glycosidation of xenobiotics and endogenous compounds: versatility and redundancy in the UDP glycosyltransferase superfamily. Pharmacol Ther 134:200-218.

Mojarrabi B and Mackenzie PI (1998) Characterization of two UDP glucuronosyltransferases that are predominantly expressed in human colon. Biochem Biophys Res Commun 247:704-709.

Moorthy B, Chu C, and Carlin DJ (2015) Polycyclic aromatic hydrocarbons: from metabolism to lung cancer. Toxicol Sci 145:5-15.

Mumtaz MM, George JD, Gold KW, Cibulas W, and DeRosa CT (1996) ATSDR evaluation of health effects of chemicals. IV. Polycyclic aromatic hydrocarbons (PAHs): understanding a complex problem. Toxicol Ind Health 12:742-971.

Münzel PA, Bookjans G, Mehner G, Lehmköster T, and Bock KW (1996) Tissue-specific 2,3,7,8tetrachlorodibenzo-p-dioxin-inducible expression of human UDP-glucuronosyltransferase UGT1A6. Arch Biochem Biophys 335:205-210.

Nakamura A, Nakajima M, Yamanaka H, Fujiwara R, and Yokoi T (2008) Expression of UGT1A and UGT2B mRNA in human normal tissues and various cell lines. Drug Metab Dispos 36: $1461-1464$.

Nesnow S, Ross JA, Stoner GD, and Mass MJ (1995) Mechanistic linkage between DNA adducts, mutations in oncogenes and tumorigenesis of carcinogenic environmental polycyclic aromatic hydrocarbons in strain A/J mice. Toxicology 105:403-413.

Nishimura M and Naito S (2006) Tissue-specific mRNA expression profiles of human phase I metabolizing enzymes except for cytochrome P450 and phase II metabolizing enzymes. Drug Metab Pharmacokinet 21:357-374.

Oikari S, Kettunen T, Tiainen S, Häyrinen J, Masarwah A, Sudah M, Sutela A, Vanninen R, Tammi M, and Auvinen P (2018) UDP-sugar accumulation drives hyaluronan synthesis in breast cancer. Matrix Biol 67:63-74.

Olson KC, Sun D, Chen G, Sharma AK, Amin S, Ropson IJ, Spratt TE, and Lazarus P (2011) Characterization of dibenzo[a,l]pyrene-trans-11,12-diol (dibenzo[def,p]chrysene) glucuronidation by UDP-glucuronosyltransferases. Chem Res Toxicol 24:1549-1559.

Palackal NT, Lee SH, Harvey RG, Blair IA, and Penning TM (2002) Activation of polycyclic aromatic hydrocarbon trans-dihydrodiol proximate carcinogens by human aldo-keto reductase (AKR1C) enzymes and their functional overexpression in human lung carcinoma (A549) cells. J Biol Chem 277:24799-24808.

Prahalad AK, Ross JA, Nelson GB, Roop BC, King LC, Nesnow S, and Mass MJ (1997) Dibenzo [a,1]pyrene-induced DNA adduction, tumorigenicity, and Ki-ras oncogene mutations in strain A/J mouse lung. Carcinogenesis 18:1955-1963.

Sellakumar A and Shubik P (1974) Carcinogenicity of different polycyclic hydrocarbons in the respiratory tract of hamsters. J Natl Cancer Inst 53:1713-1719.

Shimada T, Hayes CL, Yamazaki H, Amin S, Hecht SS, Guengerich FP, and Sutter TR (1996) Activation of chemically diverse procarcinogens by human cytochrome P-450 1B1. Cancer Res 56:2979-2984.

Strassburg CP, Strassburg A, Nguyen N, Li Q, Manns MP, and Tukey RH (1999) Regulation and function of family 1 and family 2 UDP-glucuronosyltransferase genes (UGT1A, UGT2B) in human oesophagus. Biochem J 338:489-498.

Suwan-ampai P, Navas-Acien A, Strickland PT, and Agnew J (2009) Involuntary tobacco smoke exposure and urinary levels of polycyclic aromatic hydrocarbons in the United States, 1999 to 2002. Cancer Epidemiol Biomarkers Prev 18:884-893.

Thakker DR, Yagi H, Levin W, Lu AY, Conney AH, and Jerina DM (1977) Stereospecificity of microsomal and purified epoxide hydrase from rat liver. Hydration of arene oxides of polycyclic hydrocarbons. J Biol Chem 252:6328-6334.

Trushin N, Alam S, El-Bayoumy K, Krzeminski J, Amin SG, Gullett J, Meyers C, and Prokopczyk B (2012) Comparative metabolism of benzo $[a]$ pyrene by human keratinocytes infected with high-risk human papillomavirus types 16 and 18 as episomal or integrated genomes. J Carcinog 11:1.

Uchaipichat V, Mackenzie PI, Guo XH, Gardner-Stephen D, Galetin A, Houston JB, and Miners JO (2004) Human UDP-glucuronosyltransferases: isoform selectivity and kinetics of 4 methylumbelliferone and 1-naphthol glucuronidation, effects of organic solvents, and inhibition by diclofenac and probenecid. Drug Metab Dispos 32:413-423.

Zheng Z, Fang JL, and Lazarus P (2002) Glucuronidation: an important mechanism for detoxification of benzo $[a]$ pyrene metabolites in aerodigestive tract tissues. Drug Metab Dispos 30 $397-403$.

Address correspondence to: Philip Lazarus, Department of Pharmaceutical Sciences, College of Pharmacy and Pharmaceutical Sciences, Washington State University, 412 E. Spokane Falls Blvd., Spokane, WA, 99202. E-mail: phil.lazarus@ wsu.edu 